\title{
Choosing and choice making are not the same: Asking "what do you want for lunch?" is not self-determination
}

\author{
Martin Agran ${ }^{\mathrm{a}, *}$, Keith Storey ${ }^{\mathrm{b}}$ and Michael Krupp ${ }^{\mathrm{a}}$ \\ ${ }^{a}$ University of Wyoming, Laramie, WY, USA \\ ${ }^{\mathrm{b}}$ Touro University, NV, USA
}

Revised/Accepted: March 2010

\begin{abstract}
Promoting choice making has become an important focus of disability services and supports and a basic component in service delivery. Although much of the choice making literature has involved demonstrations that individuals with intellectual and severe intellectual disabilities can be taught to make choices, limited research exists on the types of choices individuals make and the extent to which these choices are supported. Further, input about choice making has ostensibly been obtained from service providers or support personnel and not from consumers themselves. This study examines input provided by consumers with varying support needs, served in different types of employment programs, on the choice-making opportunities they were provided, if their choices were supported, and if they thought choice making was important, among other questions. The implications of the findings are discussed.
\end{abstract}

Keywords: Choice making, self-determination, intellectual disabilities, employment, informed choices

\section{Introduction}

Choice making is regarded as the central element of self-determination [34]. Self-determined individuals make choices, act on those choices, experience the results, and then make new choices [17]. Providing choice-making opportunities allows individuals to select work tasks and jobs that best match their interests and capabilities, which, in turn, will promote greater engagement and motivation [20]. To a large extent, self-determination is largely understood in terms of personal choice. As Agran and Martin [5] suggest, self-determined individuals choose their own goals and attempt to attain their goals by using self-selected strategies and supports. Promoting self-determination -

*Address for correspondence: Martin Agran, Department of Special Education, University of Wyoming, Department 3374, 1000 E. University Ave., Laramie, WY 82071, USA. E-mail: magran@uwyo.edu. specifically, promoting choice opportunities - has become an important focus of disability services and supports and a basic component in service delivery [30]. Indeed, providing individuals with intellectual and developmental disabilities opportunities to express their preferences, make choices based on those preferences, and subsequently act on those choices are considered universal rights and entitlements since they have been historically denied to these individuals [8, 19, 31].

Because all major life decisions of individuals with intellectual disabilities have been "other"-determined that is, determined by service providers, not service recipients - Mithaug [20] suggested that providing choices is the only way we can reverse the historical patterns of external control and allow individuals to have some control over their own lives and the decisions that impact them. As such, it represents both the foundation of and starting point for self-determination. Indeed, many believe that choice making is synonymous with self-determination and is arguably the most frequently 
taught self-determination strategy. Agran and Hughes [3] reported that $67 \%$ of a sample of teachers provided their students with opportunities to make choices. Wehmeyer et al. [33] reported that $64 \%$ of the teachers in their sample taught choice making, and Agran, Snow, and Swaner indicated that $84 \%$ of the educators in their sample taught choice making. Clearly, choice making is recognized as an adaptive skill that individuals with disabilities need to acquire.

For individuals with extensive support needs, choice making is clearly the self-directed learning strategy that has received the most attention in both the research literature and in adult and support services. More than any other skill associated with self-determination, choice making, and the right of people with disabilities to make choices, has been a focal point in the self-determination movement [7]. As has often been the case, individuals with intellectual or developmental disabilities have not been provided opportunities to make choices and decisions based on their own preferences [26, 36]. Because of this, many individuals do not know how to make choices and need targeted, systematic instruction on this skill. Consequently, much of the choice-making literature has involved demonstrations that individuals with intellectual and severe intellectual disabilities do have preferences and can be taught to make choices based on these preferences (see [15, 24, 34]).

At the most basic level choice making involves selecting one stimulus over another based on an individual's preferences. This action allows individuals to express their preferences - a critical first step towards achieving self-determination. For individuals who have had limited experience in and opportunities to make choices, choice making does not come automatically and needs to be taught systematically [5]. As noted above, an important area of research has been demonstrations that individuals with extensivepervasive support needs can be systematically taught to make consistent choices based on their preferences [14]. However, a limitation of this research is that it does not provide insight on the types of choices made and if these choices are taken seriously.

Optimally, choice making should enhance an individual's lifestyle [27]. In this respect, individuals should experience the consequences of their choices [2]. That is, their choices should affect their lives to the highest degree possible [8]. As Neely-Barnes et al. [22] suggested, this should result in an improved quality of life, enhanced happiness, or determination of the best courses of action when confronted with a problem. The more opportunities there are for indi- viduals to make meaningful choices, the more control they will experience [21]; and it is believed that this increased control will be crucial in achieving self-selected goals. However, the relationship between choice making and increased quality of life remains equivocal [14]. As Neely-Barnes et al. [22] noted, choice making per se is not an indicator of improved quality of life. The extent to which choices are provided is important but the critical variable is the extent to which these choices are encouraged, respected, and supported.

Additionally, it is well acknowledged that fewer choice opportunities are provided to individuals with greater support needs [1,33]. Regrettably, there is a consistent pattern that reveals that the more severe an individual's disability, the fewer choice opportunities are provided $[22,25,35]$. Needless to say, this is unfortunate since all consumers need to be provided opportunities to make choices, regardless of their support needs or work placements. This converse relationship - the more severe the disability, the fewer choice opportunities - warrants further examination.

Further, it is ironical that, despite current interest in consumer self-advocacy and self-determination, input on the extent to which choice-making opportunities are provided and the types of choices individuals make has most often been obtained from service providers and parents and not from consumers themselves [3]. This failure represents a serious omission since consumers' input on such variables as the type of choice-making instruction they have received, the types of choices they make, and the extent to which their choices are supported may provide invaluable insight on effective practice. As Martin et al. reported in several studies (see $[15,17]$ ), there is a great discrepancy between support staff opinions of what they believe consumers desire and the opinions of the consumers themselves. Hence, staff opinions of the self-determination needs of consumers may be markedly different than those expressed by consumers. It is obvious that we need to secure the opinions of consumers to ensure that programs are indeed driven by their preferences, needs, and interests.

The purpose of this investigation was to obtain input from a sample of employees with varied support needs, who were served in a variety of employment programs, on the types of choice-making opportunities they were provided, and if they were taught other self-determination strategies. Specifically, three major questions were addressed: (1) How often were the respondents asked to make choices, and if their choices 
were taken seriously?; (2) What self-determination strategies have the respondents been taught, and who taught them selected strategies?; and (3) What was the relationship between support needs and responding? Additionally, we asked them how important they thought choice making was.

\section{Method}

\subsection{Respondents}

Ten adult employment service providers were contacted, across two Western states, to solicit participation by consumers in completing the survey. An effort was made to include a representative sample of both urban and rural respondents. The service agencies consisted of a range of employment programs that provided varying levels of support to consumers (i.e., intermittent through extensive), depending on their needs (see Table 1). All agencies were receiving state funding for providing services to adults with developmental disabilities, and all

Table 1

Demographic characteristics of respondents

\begin{tabular}{|c|c|}
\hline & $n(\%)$ \\
\hline \multicolumn{2}{|l|}{ Gender } \\
\hline Male & $67(59)$ \\
\hline Female & $39(34)$ \\
\hline Did not specify & $8(7)$ \\
\hline $16-21$ & $9(8)$ \\
\hline $22-29$ & $27(24)$ \\
\hline $30+$ & $78(68)$ \\
\hline \multicolumn{2}{|l|}{ General support needs } \\
\hline Intermittent & $13(11)$ \\
\hline Limited & $20(18)$ \\
\hline Extensive & $45(39)$ \\
\hline Pervasive & $25(22)$ \\
\hline Did not specify & $11(10)$ \\
\hline \multicolumn{2}{|l|}{ Type of disability ${ }^{\mathrm{a}}$} \\
\hline Cognitive & $66(57)$ \\
\hline Mild (LD; ADHD) & $7(6)$ \\
\hline Mental illness & $3(3)$ \\
\hline Cognitive-multiple & $14(12)$ \\
\hline $\mathrm{ABI} / \mathrm{TBI}$ & $4(4)$ \\
\hline $\mathrm{CP}$ & $3(3)$ \\
\hline Did not specify & $17(15)$ \\
\hline \multicolumn{2}{|l|}{ Support at work ${ }^{\mathrm{b}}$} \\
\hline Co-worker helps PRN & $12(10)$ \\
\hline Co-worker helps often & $6(5)$ \\
\hline Job coach there daily & $6(5)$ \\
\hline Job coach always present & $70(61)$ \\
\hline Aide helps PRN & $6(5)$ \\
\hline Did not specify & $14(12)$ \\
\hline
\end{tabular}

of the agencies provided services only to adults with developmental disabilities. Based on feedback from service providers, all respondents had basic verbal skills.

A total of nine service providers across the two states agreed to participate. Due to variability in the number of respondents across agencies, as well as difficulty in determining accurate respondent sample sizes, a standard number of surveys $(n=18)$ with return postage was sent to each of the agencies, unless an other amount was specified by the agency. Service providers were asked to solicit respondents based on availability and their consent to participate, and were encouraged to ask individuals with a variety of disabilities and support needs. On-site interviews were conducted at three agencies involving 30 participants by the second author. The participants indicated that they preferred to be interviewed rather than respond to the survey questions. (Note: The input is included in the survey findings.) Agency staff members were present at approximately 10 of the interviews; some of the interviewees requested that staff be there either to help with communication issues or to help the interviewees be comfortable with the interview.

\subsection{Instrument development and dissemination}

The survey included demographic information about the respondents and questions regarding the types of choice-making opportunities provided in their respective employment preparation programs. Demographics included: age, type of disability, gender, type of employment or type of supported job setting, specific job description(s), level of support provided at work, and level of support needs in general. This information was obtained from the respondents. If they were unable or uninterested in responding, support personnel was consulted. Types of support provided at work ranged on a continuum from independent to intermittent support, through constant daily support. General support needs were based on the American Association on Intellectual and Developmental Disabilities support levels [10] and included intermittent, limited, extensive, and pervasive levels. Statements and related questions in the survey were based on valid and reliable surveys developed by Agran et al. [6] and Wehmeyer et al. [33], as agreed upon by the researchers. There were 21 Yes/No statements with open-ended questions designed to obtain information from respondents not covered in the other statements, and to provide opportunities for respondents to share other comments. The content of the statements consisted of a choice-making focus (e.g., "My support staff wants me to make choices", "I think 
my support staff takes my suggestions seriously"), as well as content related to self-determination (e.g., "I am asked to figure out if I did a good job", "I have been asked to solve a problem"). Five Yes/No statements presented information related to self-determination skills, followed by an additional component inquiring, "If yes, who taught you?"

Two questions asked respondents to identify the (a) choices he or she was asked to make today, and (b) choices he or she usually makes. There were six statements respondents could mark for each (e.g., "Who I wanted to work with", "Which task I wanted to do"), and they could mark more than one. Additionally, a choice of 'other' was provided with space to fill in that particular choice. Finally, the last question asked respondents if they thought making choices was important and why?

\subsection{Administration of survey}

The surveys were conducted at the respondents' respective work sites. Support personnel administered the survey. Those service providers who agreed to participate were sent copies of the survey, which included the questionnaire, consumer assent forms, and consent forms for guardians where necessary. Responses from respondents involved verbally answering yes or no, a skill affirmed by support personnel. Additionally, they were asked to indicate the types of choices they have been asked to make and who taught them selected self-determination strategies. The staff was instructed to read the questions to respondents and explain the questions if needed (e.g., have minor word changes, provide a related example), or rephrase or paraphrase the questions. Examples relevant to the respondents were provided. Questions were repeated until the respondent to understand according to the support person. If the respondent did not respond to the question or did not appear to understand the question after several rephrasing, the staff was instructed to skip the question and address the next question.

\subsection{Data analysis}

\subsubsection{Descriptive}

Frequencies were recorded for each answered question and converted to percentages for all questions, except the open-ended responses. Frequency tallies were calculated and reported in terms of number and percentages of responses out of the total number of completed questionnaires returned.

\subsubsection{Chi square analysis}

To determine if a significant relationship existed between variables, a Pearson Chi square contingency analysis was conducted. Specifically, a Chi square statistic was calculated to determine the significance of the relationship between specific groups and responses to Yes/No statements. In such a case that a specific statement resulted in a significant finding adhering to a $p$ value of $<0.05$, a follow-up analysis was conducted also using the Chi square statistic. A Bonferroni Adjustment was used $(p<0.017)$ as a conservative method of controlling for a Type I error. Phi was calculated for results meeting levels of significance, providing a measure of effect.

\subsubsection{Kuder-Richardson 20 (KR-20)}

To obtain a measure of internal consistency, a coefficient of reliability was calculated. KR-20 results provided reliability support for statements on the questionnaire and their relationship to choice-making and self-determination constructs.

\subsection{Interrater agreement}

To ensure the believability of recorded survey findings, agreement data were calculated across questionnaire items. Specifically, two types of agreement were calculated: agreement regarding the frequency of responses to each response option and agreement regarding the responses to the open-ended questions. The second author and an independent reader coded the open-ended responses of $10 \%$ of the surveys. The percentage of agreement was calculated by dividing the total number of responses recorded by each recorder by the smaller total, and multiplying by 100 .

\section{Results}

\subsection{Demographics}

A total of 10 service providers were contacted and nine agreed to participate in disseminating the surveys. Interrater agreement was $93 \%$ for open-ended items and $100 \%$ for the frequency of responses. Based on an estimated sample of 162 potential respondents, 114 completed surveys were returned, providing a response rate of $70 \%$. Respondent demographics are displayed in Table 1. Over two-thirds of respondents $(68 \%)$ were over 30 years of age with males constituting the majority of the respondents (59\%) and females one-third 
(34\%). The majority of respondents' general support needs included extensive (39\%) and pervasive (22\%). Although participants included a number of disability types, respondents with cognitive (57\%) and cognitivemultiple disabilities $(12 \%)$ constituted the majority of the total number of respondents $(69 \%)$. Finally, respondents' support needs at work primarily indicated the job coach or staff person was "always present" $(61 \%)$. The types of jobs held by the respondents varied greatly and included motel housekeeping, grocery store stocker or bagger, janitorial or grounds keeping jobs, and working in shops or in fast food restaurants.

\subsection{Opinions about choice making and self-determination}

\subsubsection{Choice making}

Table 2 includes statements and response frequencies related to choice-making and self-determination. The majority of the respondents indicated their support/staff person wanted them to make choices (77\%), were sometimes asked if they liked their job (87\%), and thought their support staff took their suggestions seriously (74\%). A reversed item "I am not asked to make choices every day" resulted in 55\% indicating "No". Twenty-three percent (23\%) of all respondents chose not to answer the statement. Finally, the last question asked respondents if they thought making choices was important and why. Ninety percent $(90 \%)$ indicated that making choices was important. Their reasons varied but included responses identifying the importance of being independent, being happy, learning, and having pride in being able to decide for themselves.

Statements related to choice making requiring a Yes/No response were followed by an open question asking for clarification or to provide an example. For instance, the Yes/No statement "My support/staff person wants me to make choices throughout the day" was followed by "What does he or she say about making choices?" The Yes/No statement, "I think my support/staff person takes my suggestions seriously" was followed by "How do you know?" Approximately 25\% of the respondents chose to answer these questions. Respondents' answers to open-ended questions varied, but provided an indication they understood what was being asked, and could support their Yes/No answer with their own personal reasons.

\subsubsection{Self-determination}

In addition to frequencies related to choice making, Table 2 also includes response frequencies of questions related to self-determination. Six of the 10 statements had frequencies above $70 \%$ in which respondents answered "Yes" to these statements. None of the statements received "Yes" answers with frequencies less than $50 \%$, except two statements related to counting the number of times a target behavior was performed or counted (Yes $=17 \%$ and $18 \%$, respectively). Response frequencies for statements related to self-determination included: (a) "I feel proud when I do a good job" (96\%), (b) "I have been asked to set goals for myself" (77\%), and (c) "I am asked to figure out if I did a good job" $(77 \%)$.

Table 2

Statements and response frequencies related to choice-making and self-determination

\begin{tabular}{lrr}
\hline Statements related to choice-making and self-determination & $\begin{array}{c}\text { Yes } \\
n(\%)\end{array}$ & $\begin{array}{c}\text { No } \\
n(\%)\end{array}$ \\
\hline Choice-making & & \\
My support/staff person wants me to make choices throughout the day. & $89(77)$ & $21(18)$ \\
My support/staff person sometimes makes choices for me during the week. & $78(68)$ & $27(24)$ \\
I am not asked to make choices every day. & $25(22)$ & $63(55)$ \\
Sometimes I have been asked if I like my job. & $100(87)$ & $14(12)$ \\
Sometimes I am asked if there is another job I would like to do. & $60(52)$ & $49(43)$ \\
I think my support/staff person takes my suggestions seriously. & $85(74)$ & $23(20)$ \\
Self-determination & & \\
Besides my choices, I am asked to set goals for myself. & $88(77)$ & $26(23)$ \\
I am asked to figure out if I did a good job. & $88(77)$ & $25(22)$ \\
I am asked to count the number of times I perform a target behavior. & $19(17)$ & $89(77)$ \\
I feel proud when I do a good job. & $110(96)$ & $3(3)$ \\
I am asked to help solve a problem at work. & $64(56)$ & $47(41)$ \\
I have been taught to make choices. & $84(73)$ & $28(24)$ \\
I have been taught to determine if I did a good job. & $88(77)$ & $26(23)$ \\
I have been taught to count the number of times I perform a target behavior. & $21(18)$ & $85(74)$ \\
I have been taught to feel good if I did a good job. & $91(79)$ & $21(18)$ \\
I have been taught to problem solve. & $78(68)$ & $35(30)$ \\
\hline
\end{tabular}




\subsection{Relationship of support need and responding}

The Pearson Chi square analysis displayed in Table 3 suggested there was a statistically significant relationship between the level of support needs (i.e., intermittent, limited, extensive, pervasive) and responses related to three different self-determination statements. Effect size was calculated using Phi $(\varphi)$, showing moderate strength in the relationships between the four support needs items and each of the three statements. At this point in the analysis it was unknown which levels of support differed in terms of the three significant questionnaire statements because all four support needs were calculated together. A secondary analysis contrasting the different levels of support with the three significant statements was also conducted using the Pearson Chi square statistic. The Bonferroni adjustment was applied, resulting in a $p$ value of $<0.017$.

The results of the secondary analysis are included in Table 3. Results suggested a significantly reliable difference between respondents requiring extensive supports and those requiring pervasive supports across the question, "if respondents had been asked to solve a problem at work" $\left(\chi^{2}(1, n=72)=9.65, p=0.003, \varphi=0.37\right)$.

Table 3

Chi square analysis for selected Yes/No statements related to support needs. n/a: Not available

\begin{tabular}{lccccc}
\hline Secondary analysis & $\chi^{2}$ & $d f$ & $n$ & $p$ & $\varphi^{\mathrm{b}}$ \\
\hline $\begin{array}{l}\text { "I have been taught to } \\
\text { problem solve" }\end{array}$ & 23.36 & 3 & 105 & $<0.001$ & 0.47 \\
Extensive and pervasive & 5.26 & 1 & 73 & $<0.03^{\mathrm{a}}$ & 0.27 \\
Intermittent and limited & 1.72 & 1 & 32 & $0.38^{\mathrm{a}}$ & $\mathrm{n} / \mathrm{a}$ \\
Intermittent and extensive & 3.00 & 1 & 57 & $0.15^{\mathrm{a}}$ & $\mathrm{n} / \mathrm{a}$ \\
Intermittent and pervasive & 9.31 & 1 & 40 & $<0.004^{\mathrm{a}}$ & 0.48 \\
Limited and pervasive & 18.80 & 1 & 48 & $<0.001^{\mathrm{a}}$ & 0.53 \\
& & & & & \\
"I have been taught to & 15.41 & 3 & 103 & $<0.001$ & 0.39 \\
$\quad$ make choices" & & & & & \\
Extensive and pervasive & 4.36 & 1 & 71 & $<0.045^{\mathrm{a}}$ & 0.25 \\
Intermittent and limited & 0.078 & 1 & 32 & $1.00^{\mathrm{a}}$ & $\mathrm{n} / \mathrm{a}$ \\
Intermittent and extensive & 2.19 & 1 & 57 & $0.26^{\mathrm{a}}$ & $\mathrm{n} / \mathrm{a}$ \\
Intermittent and pervasive & 7.30 & 1 & 40 & $<0.013^{\mathrm{a}}$ & 0.43 \\
Limited and pervasive & 11.02 & 1 & 46 & $0.001^{\mathrm{a}}$ & 0.44 \\
& & & & & \\
"I have been asked to solve & 10.17 & 3 & 103 & $<0.017$ & 0.31 \\
$\quad$ a problem at work" & & & & & \\
Extensive and pervasive & 9.65 & 1 & 72 & $<0.003^{\mathrm{a}}$ & 0.37 \\
Intermittent and limited & 0.04 & 1 & 31 & $1.0^{\mathrm{a}}$ & $\mathrm{n} / \mathrm{a}$ \\
Intermittent and extensive & 0.170 & 1 & 56 & $0.73^{\mathrm{a}}$ & $\mathrm{n} / \mathrm{a}$ \\
Intermittent and pervasive & 3.25 & 1 & 40 & $0.09^{\mathrm{a}}$ & $\mathrm{n} / \mathrm{a}$ \\
Limited and pervasive & 3.42 & 1 & 47 & $0.08^{\mathrm{a}}$ & $\mathrm{n} / \mathrm{a}$ \\
\hline
\end{tabular}

${ }^{a}$ Fisher's exact test for significance.

b Size of effect.

c Using Bonferroni's adjustment where $p<0.017$.
There was a trend toward significance between these same two groups for the statements related to "if they had ever been taught to problem solve" $\left(\chi^{2}(1, n=73)=\right.$ 5.26, $p=<0.03, \varphi=0.27)$ and "if respondents had ever been taught to make choices" $\left(\chi^{2}(1, n=71)=4.36\right.$, $p=<0.045, \varphi=0.25)$. With a moderate effect, these results suggest that respondents requiring less support had been taught to problem solve, make choices, and solve a problem at work more often than those with a pervasive level of support.

Additionally, there was statistically reliable difference between groups of respondents requiring intermittent and limited support compared to those requiring pervasive support. There was a significant difference related to asking respondents "if they had ever been taught to problem solve" $\left(\chi^{2}(1, n=40)=9.31\right.$, $p=<0.004, \varphi=0.48 ; \chi^{2}(1, n=48)=18.80, p=<0.001$, $\varphi=0.53$ ) and "if respondents had ever been taught to make choices" $\left(\chi^{2}(1, n=71)=7.30, p=<0.013\right.$, $\left.\varphi=0.43 ; \chi^{2}(1, n=46)=11.02, p=<0.004, \varphi=0.44\right)$. The effects of these relationships were moderate to strong, indicating that those with the lowest levels of support (intermittent and limited) answered "Yes" to statements associated with opportunities for selfdetermination more often than those with the highest levels of support (pervasive).

A Kuder-Richardson-20 (KR-20) analysis of reliability was calculated for all Yes/No dichotomous items together. The KR-20 is an equivalent form of Cronbach's alpha for dichotomous variables. Collectively, the reliability resulted in a moderate internal consistency $(\alpha=0.76)$. As a sub-group, the reliability of the statements related to self-determination had a moderate alpha $(\alpha=0.76)$. The statements related to choice-making had a much lower alpha $(\alpha=0.35)$. The statements related to choice-making had two reverseworded items that resulted in a number of respondents having difficulty answering and subsequently choosing not to answer the reversed items.

\subsection{Types of choices}

Respondents were also asked to respond to the statement, "Today I was asked to make the following choices" which included such response options as "Who I want to work with?" and "Which task I want to do first?" Fig. 1 presents their responses. Frequencies for these items were generally low, with the most frequent being "which task to do" (28\%). Thirty-five percent $(35 \%)$ chose to mark none of the responses to 


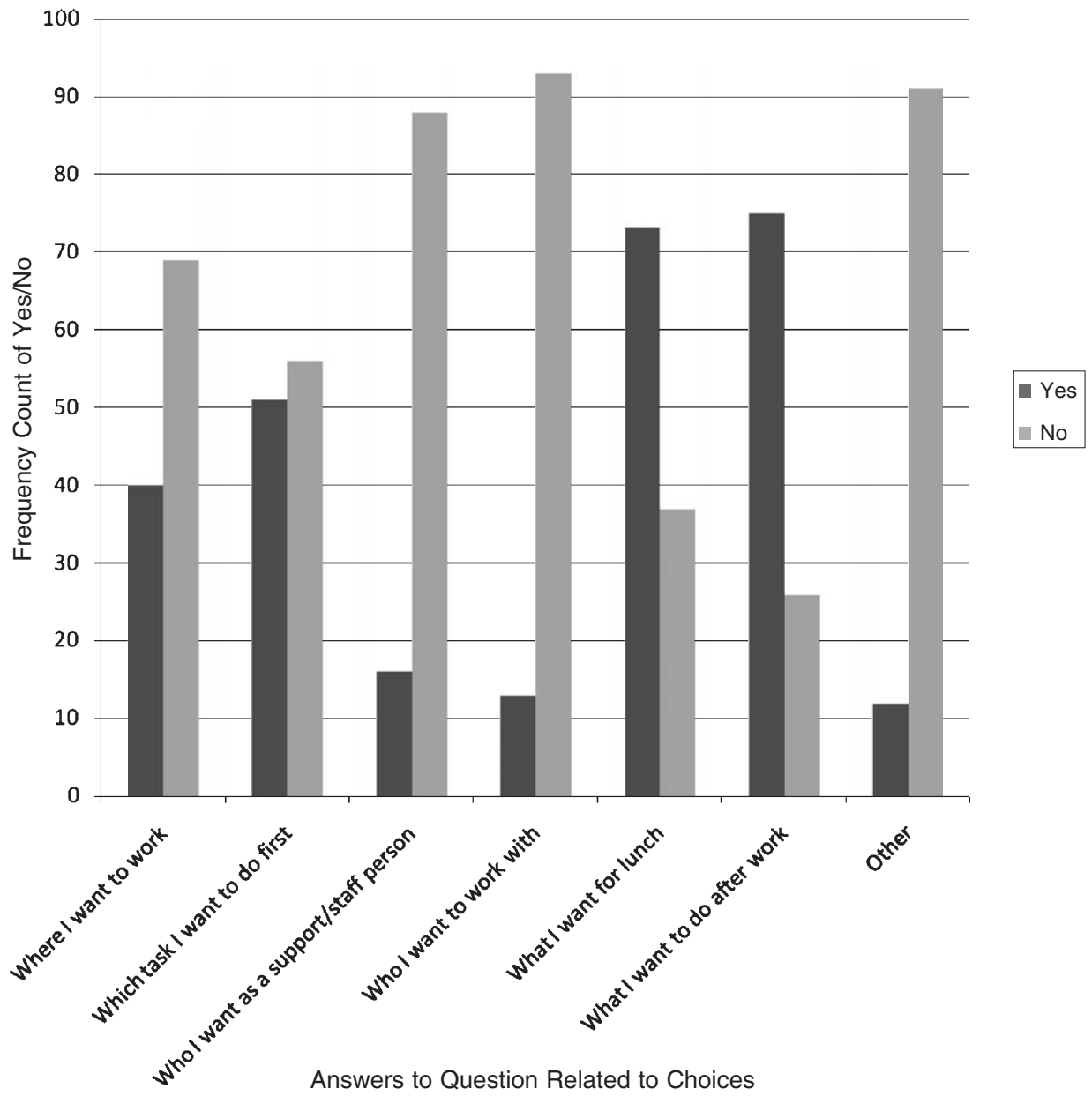

Fig. 1. Responses to the statement: "When I've made choices, it's usually about".

this item. Respondents were also asked to respond to the statement, "When I have made choices, it is usually about," with a similar set of seven choices whereby respondents could choose as many as applicable. Two of these response choices resulted in more "Yes" responses than "No" (e.g., "What I want for lunch" and "What I want to do after work"). The rest of the responses were indicated infrequently, including "Other".

\subsection{Who taught choice-making skills}

If the respondent indicated "Yes" to having been taught any of the sef-determination mentioned, he or she was asked the question, "Who taught these particular skills?" Job Coach was identified most frequently (69\%) and teachers the least frequently (32\%) (see Fig. 2). For the choice of "Other", respondents fre- quently indicated Staff. Since this was closely related to job coach, it was included in the frequency totals for Job Coach. "Other" often included "doctor", "psychologist", or a "relative" such as an uncle or aunt.

\section{Discussion}

We examined the extent to which and the types of choice-making opportunities were provided to a sample of employees with intellectual and developmental disabilities in competitive, supported, and sheltered employment programs across two states. The results indicated that the participants perceived it was important they make choices in their lives, they had been taught how to make choices, and they generally were provided opportunities to make choices. Additionally, the majority of respondents reported that they had been 


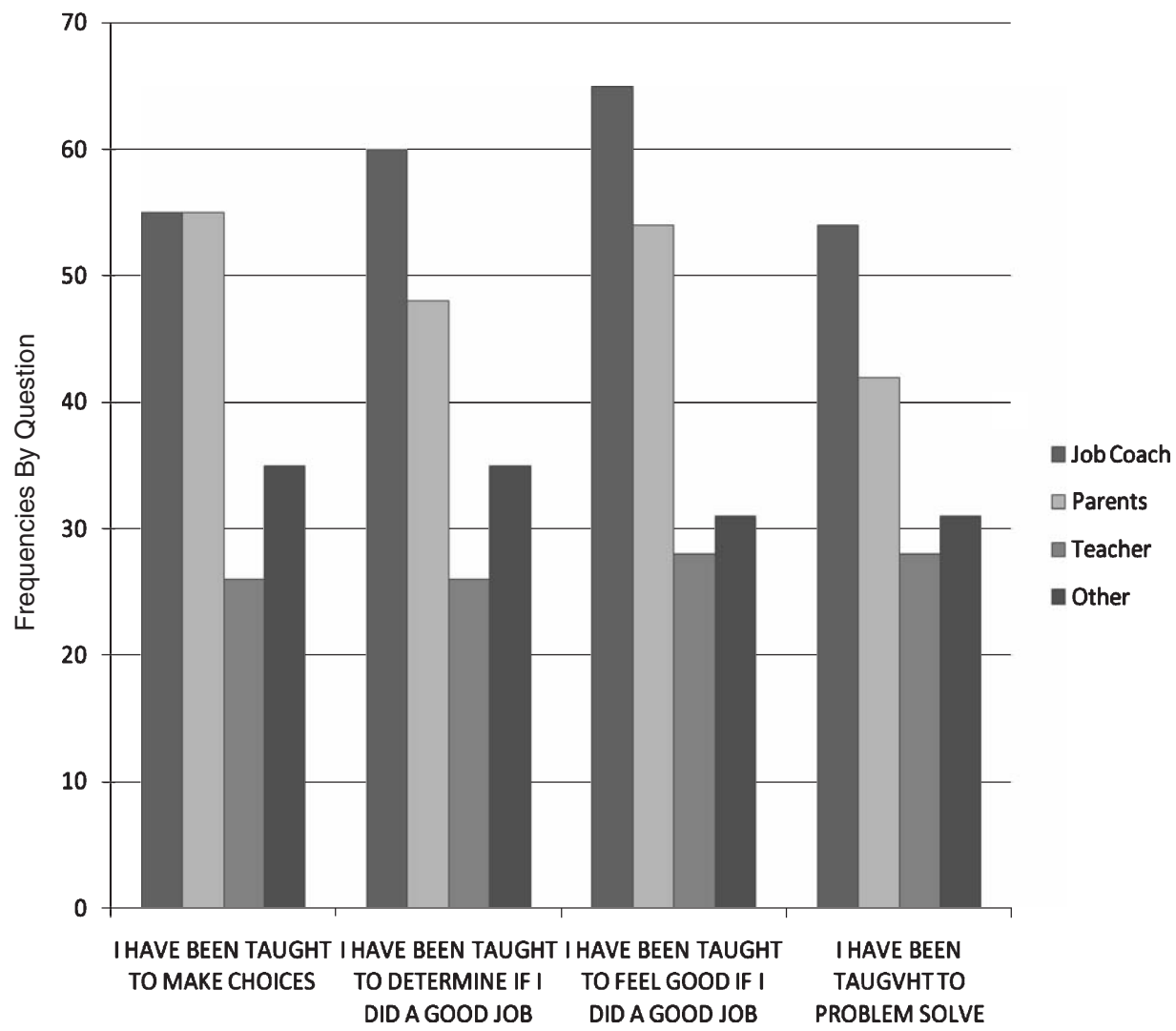

Fig. 2. Questions focused on self-determination and who primarily taught the skills. Note: Respondents were able to choose more than one response option.

taught to perform a number of self-determination strategies (e.g., self-reinforcement, problem solving). These strategies were taught either by job coaches or parents, with teachers and others (e.g., psychologist, relative) identified by less than one-third of the respondents. Most importantly, the majority of the respondents indicated that their support personnel took their choices seriously.

This study reinforces the finding that choice-making skills not only need to be taught but that supports are necessary for the individual to realize their choices and organizational supports within agencies for those individual choices are necessary; in other words, systems need to be in place to support meaningful choices [36]. For example, a student transitioning from high school to adult life may have the understanding and skills to make the choice that she would like a supported employment placement, and supports are available from the school district for the individual to make an informed choice (situational assessments, job tryouts, etc.), but the adult service organization to which the student in transitioning to may have no supported employment supports available as they provide only sheltered work opportunities. Consequently, even informed choices become meaningless without appropriate supports and options being available. Seventy percent $(70 \%)$ of the respondents in the present investigation had extensive to pervasive support needs, and $61 \%$ indicated that their job coaches were always present; other respondents indicated that support was provided by co-workers or aides. We do not know the specific responsibilities of the support personnel or if more job coaches were assigned to certain types of jobs that may not reflect consumer's preferences, but these numbers suggest that appropriate supports were in place - in all, an encouraging finding.

A troubling finding was that respondents requiring less support had been taught to problem solve, make choices, and solve a problem at work more often than those with a pervasive level of support. Although discouraging, this finding is not surprising as there is other research to suggest that professionals appear to believe 
that self-determination instruction is more important for individuals with intermittent or limited support needs than those with more extensive support needs $[6,33]$. In the present study, we found the same outcome for consumers - that is, the value of self-determination instruction may be differentially rated based on an individual's support needs. The unfortunate aspect of this finding is that consumers who require more supports are more than likely to be in greater need for selfdetermination instruction if we wish to promote their independence and autonomy, and, thus, need committed instruction on using the different self-determination strategies. As suggested by Wehemeyer et al., this finding may suggest that staff and others may believe that individuals with more significant disabilities are less capable of being self-determined and thus not bother to teach appropriate skills or provide meaningful choices. This is an issue that needs further investigation and of course remediation.

Several limitations to this study warrant consideration and will influence interpretation of the results. First, only the perception of choice making from the participants was assessed and no correlation with actual skills taught or opportunities for making choices was conducted. Although obtaining the opinions of consumers regarding the choice-making opportunities provided to them and the self-determination skills and strategies they have learned is most important, we do not know how choice-making instruction was delivered and what were the specific opportunities provided. For example, $73 \%$ of participants indicated that they had been taught choice-making skills, but we don't know if the skills had been taught formally or informally, or if a validated curriculum was used (e.g., [13]). Because of limited opportunities to make choices, many individuals with extensive-pervasive supports needs do not know how to make choices and need to be taught using systematic instructional procedures $[11,16]$. Wehmeyer et al. [33] reported that one of the major obstacles to promoting consumer self-determination is the belief by many teachers and service providers that there are no instructional materials available to teach choice making or other self-determination strategies. Suffice it to say that such materials are available (see [5, 34]). Further, it is encouraging that the majority of respondents indicated that their job coaches taught them a number of self-determination-related skills, even though we do not know how this was done. However, the data also reveal that only one-third or less of the respondents indicated that parents or teachers had taught them these skills. There is no question that self-determination instruction should be provided as early as possible (i.e., during the school years). More positive quality-of-life and community membership outcomes have been associated with higher levels of self-determination [37]. Thus, such instruction should not only be provided for transition-age youth (if not sooner) but should be taught and encouraged by all important stakeholders (e.g., parents, teachers). Ideally, individuals should be coming into employment programs with these skills so that programs can be directly based on informed consumer wishes and preferences before rather than after major decisions need to be made.

A second limitation was that it remains unclear how these choices directly impacted the respondents' work experiences and quality of life. For example, at one agency the participants were asked once a year at their Individual Program Plan meetings if they wanted to work elsewhere such as a supported employment placement. However, the agency did not offer supported employment, so in effect there was no "real" choice involved. This practice is at its worst disingenuous and suggests that this agency approaches choice making as a required activity in program planning that has little or no functional value. That is, although consumers were provided an opportunity to provide input at their meetings but their input has little or no influence on the nature of or quality of their work experiences, Several service providers appear to have the mistaken belief that providing consumers with choice-making opportunities will in and of itself promote their self-determination [32]. There is no question that choice making is the first step in enhancing self-determination but it doesn't ensure that an individual will become self-determined. Most importantly, activities that promote self-determination are those that allow individuals to be causal agents that is, make or cause "things to happen in their lives" ([34] p. 7). Individuals need the opportunity to learn to make choices based on their preferences and interests but they also need to experience and learn from the consequences of those choices. If choice making doesn't result in meaningful changes that allow individuals to evaluate the desirability of choices, its value in promoting self-determination is severely restricted. In the present study the choices that were reported were most frequently choices relating to non-work activities. These no doubt may be important choices for consumers to make but they do suggest that many work-related choices continue to be made by support personnel. As indicated in our title, making choices and being self-determined is not necessarily the same thing. 
A third limitation was that participants might have been providing answers that they thought that the researchers and/or staff were looking for. Since staff helped with their written responses or were often present when interviews were conducted, this may have inhibited the respondents in their answers. Since we did not ask respondents to explain their responses, we do not know for certain if their responses accurately reflected their opinions or may have been reactive and represented what the consumers thought service providers wanted them to say. However, many of the respondents did report the skills they did not learn (e.g., problem solving, self-monitoring) and the choices they were not asked to make (e.g., where they wanted to work, who they wanted as a support person) and we suggest that the respondents provided responses that reflected their own opinions. Needless to say, in future research it is recommended that support personnel unknown to the respondents are present to minimize any biases related to reactivity.

A fourth limitation was the relatively small sample size. Although the response rate was acceptable and the sample size was sufficient to conduct a nonparametric analysis, a larger sample would have enhanced the credibility of the findings. Consequently, future replications are warranted.

Fifth, the survey was designed to be brief to facilitate its administration to respondents. That said, additional questions relating to self-determination strategies, opportunities to perform these skills, and the types of supports support personnel provided could have been asked. In future research researchers may want to add other questions of interest.

Future research efforts in this area should continue to explore the relationship between the level of support needs and the extent to which and nature of choice-making opportunities provided to supported employees. As noted previously, several researchers have reported that individuals with extensive-pervasive support appear to have received less self-determination than individuals with lesser support needs. As mentioned previously, it has been reported that some professionals (and parents) may believe that individuals with extensive-pervasive support needs will not benefit from self-determination instruction, or they will make choices that are either dangerous or not in the consumers' best interests (see $[29,33]$ ). Also, it has been reported in several studies that service providers and practitioners may want to teach consumers how to be more self-determined but either do not know how to provide such instruction or are unaware of the available curricula available [18, 28, 33]. As Wehemeyer et al. reported, although the professionals in their sample valued self-determination and believed it was important for their consumers to achieve, many did not know how to teach these skills. Several curricula are available to teach choice making and other self-determination skills (see [4, 13, 34]).

Additionally, choice making (and other forms of selfdetermination) is contingent on the assumption that a consumer's expression of a choice or wish is understood by service providers or support personnel. Accordingly, communication competence is synonymous with selfdetermination [9]. However, as Brown et al. noted, consumers who have severe communication challenges may employ nonsymbolic, idiosyncratic, inconsistent, or self-selected modes of communication to express their choices. Consequently, choice making for these individuals presumes that the communication receivers (e.g., caregivers, support people) can interpret such communication. In this respect, self-determination may be wholly dependent on others and is meaningful only to the extent that the choice is correctly interpreted. Most importantly, we must be certain that the message received is the message intended. Because service providers may have difficulties interpreting consumers' choices, there may be reluctance to solicit such choices.

Although the present investigation examined the types of choices provided to a sample of employees, it did not examine the relationship between an individual's choices (and self-determination) and their impact on the quality or type of services provided. For example, if a consumer chose not to engage in a particular work activity, did not want to interact with a particular support person, or chose a job that was not typically not provided by the agency to consumers, how would this impact service delivery? This appears to be the important "missing link" where the breakdown occurs between the choice of the individual and the ability of the service delivery system to provide those services and supports. As indicated previously, it is both self-defeating and meaningless to allow consumers to make choices that cannot be supported or realized. Needless to say, choice making will hopefully serve as the antecedent that will allow individuals to receive services based on their wishes. Equally important it should serve as the antecedent for agencies to secure appropriate resources and supports to meet consumer needs. Ultimately, choice making represents a dynamic relationship between a consumer and an employment program or support agency, and an impact should be experienced by both. 
Research is also needed on methodological issues related to conducting interview research involving people with intellectual disabilities [23]. For instance, do face to face interviews with someone unknown to the individual provide more socially valid information that an interview with a staff member or with a staff member present? In addition, future research needs to assess variables across supported employment settings that may influence choice making opportunities such as differences in job tasks, job routines (e.g., set or variable), and supervision structures.

Future research on the relationship between choice making and quality of life domains (physical wellbeing, material well-being, social well-being, productive well-being, emotional well-being, and civic well-being) as outlined by Felce [12] is also warranted. As indicated previously in this paper, the relationship between choice making and enhanced quality of life remains inconclusive at best. Although the former should be positively associated with the latter, such a positive relationship has not been reported in the literature $[14,22]$. This question was not addressed in the present study and thus remains a limitation. It is critical that we begin to have a better understanding about how choice making (as well as other self-determination strategies) do indeed impact the quality of an individual's life. Such an understanding will no doubt permit service providers to provide more self-determination instruction and for consumers to apply these skills more frequently.

In conclusion, it is clear that adults with intellectual and developmental disabilities value being taught how to make choices, want choices available to make, and need appropriate supports to realize those choices. Additionally, the respondents reported that they have been taught several self-determination strategies (e.g., problem solving, valuing their work performance, setting goals). These findings suggest that service providers - at least in the present investigation - are providing instruction to enhance the self-determination of consumers. We believe it is critical to ask consumers to provide input on the value of choice making and self-determination. If not, we are at best only second-guessing what their needs and interests are. When comparing the opinions of consumers and service providers on the goals and interests of the former, Martin et al. [16] reported that they were rarely in agreement - that is, the preferences and interests as stated by consumers were very different than what service providers thought they were. Needless to say, continued research is needed on practices to ensure that individ- uals with cognitive disabilities have a critical role in determining the nature of the work experiences they are provided and that their choices are acknowledged and supported.

\section{References}

[1] M. Agran, S. Hong and K. Blankenship, Promoting the selfdetermination of students with visual impairments: Reducing the gap between knowledge and practice, Journal of Visual Impairments and Blindness 101 (2007), 453-464.

[2] M. Agran and C. Hughes, Introduction to special issue: Selfdetermination reexamined: How far have we come? Research and Practice for Persons with Severe Disabilities 30 (2005), 105-107.

[3] M. Agran and C. Hughes, Asking student input: Students' opinions regarding their individualized education program involvement, Career Development for Exceptional Individuals 31 (2008), 69-76.

[4] M. Agran, M. King-Sears, M. Wehmeyer and S. Copeland, Teacher's Guide to Inclusive Practice: Student-Directed Learning, Paul H. Brookes, Baltimore, 2003.

[5] M. Agran and J.E. Martin, Self-determination: Enhancing competence and independence, in: The Road Ahead: Transition to Adult Life for Persons with Disabilities, K. Storey and P. Bates, eds, Training Resource Network, St. Augustine, 2008, pp. 189-214.

[6] M. Agran, K. Snow and J. Swaner, Self-determination: Benefits, challenges, characteristics, Education and Training in Mental Retardation and Developmental Disabilities 34 (1999), 293-301.

[7] M. Agran and M. Wehmeyer, Self-determination, in: Curriculum and Instruction for Students with Significant Disabilities in Inclusive Settings, D. Ryndak and S. Alper, eds, Allyn and Bacon, Needham Heights, Mass, 2003, pp. 259-276.

[8] I. Brown and R.J. Brown, Choice as an aspect of quality of life for people with intellectual disabilities, Journal of Policy and Practice in Intellectual Disabilities 6 (2009), 11-18.

[9] F. Brown, C.R. Gothelf, D. Guess and D. Lehr, Self-determination for individuals with the most severe disabilities: Moving beyond chimera, Journal of the Association for Persons with Severe Handicaps 23 (1998), 17-26.

[10] S. Borthwick-Duffy, W. Buntinx, R. Luckasson, R.L. Schalock, S. Snell, M. Tasse and M. Wehmeyer, User's Guide: Mental Retardation, American Association on Intellectual and Developmental Disabilities, Washington, D.C., 2002.

[11] H.I. Cannella, M.F. O'Reilly and G. Lancioni, Choice and preference assessment research with people with severe to profound developmental disabilities: A review of the literature, Research in Developmental Disabilities 26 (2005), 1-15.

[12] D. Felce, Defining and applying the concept of quality of life, Journal of Intellectual Disability Research 41 (1997), 126-135.

[13] J.E. Martin, L.H. Marshall, D. Wray, L. Wells, J. O'Brien, G. Olvey and Z. Johnson, Choose and Take Action: Finding the Right Job for You, Sopris West Publishers, Longmont, CO, 2004.

[14] T.L. Martin, G.L. Martin, S. Spevack, A. Verbeke and D. Yu, Does choice, independent of preference, improve behaviour for persons with developmental disabilities? A review, Developmental Disabilities Bulletin 30 (2002), 1-15. 
[15] J.E. Martin, D.E. Mithaug, J.V. Husch, E.S. Frazier and L.H. Marshall, The effects of optimal opportunities and adjustments on job choice of adults with severe disabilities, in: SelfDetermined Learning Theory: Predictions, Prescriptions, and Practice, D.E. Mithaug, D. Mithaug, M. Agran, J.E. Martin and M. Wehmeyer, eds, Erlbaum Publishers, Mahwah, N.J., 2003, pp. 188-205.

[16] J.E. Martin, L.L. Woods, L. Sylvester and J.E. Gardner, A challenge to self-determination: Disagreement between the vocational choices made by individuals with severe disabilities and their caregivers, Research and Practice for Persons with Severe Disabilities 30 (2005), 147-153.

[17] J.E. Martin, L.L. Woods, L. Sylvester and J.E. Gardner, A challenge to self-determination: Disagreement between the vocational choices made by individuals with severe disabilities and their caregivers, Research and Practice for Persons with Severe Disabilities 30 (2006), 41-43.

[18] C.Y. Mason, M. McGahee-Kovac and L. Johnson, How to help students lead their IEP meetings, Teaching Exceptional Children 36(3) (2002), 18-24.

[19] D.E. Mithaug, Your right, my obligation, Research and Practice for Persons with Severe Disabilities 23 (1998), 147-153.

[20] D.E. Mithaug, On persistent pursuits of self-interest, Research and Practice for Persons with Severe Disabilities 30 (2005), 163-167.

[21] D.K. Mithaug and D.E. Mithaug, The effects of choice opportunities and self-regulation training on the self-engagement and learning of young children with disabilities, in: SelfDetermined Learning Theory: Construction, Verification, and Evaluation, D.E. Mithaug, D.K. Mithaug, M. Agran, J.E. Martin and M. Wehmeyer, eds, 2003, pp. 141-157, Mahwah, NJ, Lawrence Erlbaum Associates, Inc, Publishers.

[22] S. Neely-Barnes, M. Marcenko and L. Weber, Does choice influence quality of life for people with mild intellectual disabilities? Intellectual and Developmental Disabilities $\mathbf{4 6}$ (2008), 12-26.

[23] Y. Ohtake and J.G. Chadsey, Social disclosure among coworkers without disabilities in supported employment settings, Mental Retardation 37 (1999), 25-34.

[24] L. Powers, Self-determination by individuals with severe disabilities: Limitations or excuses, Research and Practice for Persons with Severe Disabilities 30 (2005), 168-172.

[25] R.B. Smith, M. Morgan and J. Davidson, Does the daily choice making of adults with intellectual disability meet the normalisation principle? Journal of Intellectual \& Developmental Disability 30(4) (2005), 226-235.

[26] R.J. Stancliffe and B.H. Abery, Longitudinal study of deinstitutionalization and the exercise of choice, Mental Retardation 35 (1997), 159-169.
[27] K. Storey, Informed choice: The Catch-22 of self-determination, Research and Practice for Persons with Severe Disabilities 30 (2005), 232-234.

[28] C. Thoma, G.M. Pannozzo, S.C. Fritton and C.C. Bartholomew, A qualitative study of preservice teachers' understanding of self-determination for students with significant disabilities, Career Development for Exceptional Individuals 31 (2008), 94-105.

[29] M. Ward, An historical perspective of self-determination in special education: Accomplishments and challenges, Research and Practice for Persons with Severe Disabilities (RPSD) 30 (2005), 108-112.

[30] M.L. Wehmeyer, Self-determination and mental retardation, in: International Review of Research in Mental Retardation, L.M. Glidden, ed., Lawrence Erlbaum Publishers, Hillsdale, NJ, Vol. 24, 2001, pp. 1-48.

[31] M. Wehmeyer, Self-determination and individuals with significant disabilities: Examining meanings and misinterpretations, Research and Practice for Persons with Severe Disabilities $\mathbf{2 3}$ (1998), 5-16.

[32] M.L. Wehmeyer, Self-determination and individuals with severe disabilities: Reexamining meanings and misinterpretations, Research and Practice for Persons with Severe Disabilities 30 (2005), 113-120.

[33] M. Wehmeyer, M. Agran and C. Hughes, A national survey of teachers' promotion of self-determination and studentdirected learning, Journal of Special Education 34 (2000), $58-68$.

[34] M. Wehmeyer, M. Agran, S. Palmer, D. Mithaug, J. Martin and C. Hughes, Promoting Self-Determination and StudentDirected Learning for Students with Intellectual and Developmental Disabilities, Guilford, New York, 2007.

[35] M.L. Wehmeyer and N.W. Garner, The impact of personal characteristics of people with intellectual and developmental disability on self-determination and autonomous functioning, Journal of Applied Research in Intellectual Disabilities $\mathbf{1 6}$ (2003), 255-265.

[36] M. L. Wehmeyer and C. Metzler, How self-determined are people with mental retardation? The National Consumer Survey, Mental Retardation 33 (1995), 111-119.

[37] M. L. Wehmeyer and M. Schwartz, The self-determination focus of transition goals for students with mental retardation, Career Development for Exceptional Individuals 21 (1998), 75-86.

[38] M. West, G. Revell and P. Wehman, Conversion from segregated services to supported employment: A continuing challenge to the VR service system, Education and Training in Mental Retardation and Developmental Disabilities $\mathbf{3 3}$ (1998), 239-247. 
Copyright of Journal of Vocational Rehabilitation is the property of IOS Press and its content may not be copied or emailed to multiple sites or posted to a listserv without the copyright holder's express written permission. However, users may print, download, or email articles for individual use. 